\title{
POST INSERTION PROBLEMS AND THEIR MANAGEMENT IN COMPLETE DENTURE
}

Honey Jethlia, Ankur Jethlia, Naveen Raj P, Ashish Meshram, Neha Sharma
1. Senior Lecturer, Department of Prosthodontics, Daswani Dental College and Research Center, Kota Rajasthan
2. Senior Lecturer, Department of Oral Medicine \& Radiology, Daswani Dental College and Research Center, Kota Rajasthan
3. Senior Lecturer, Department of Prosthodontics, SMBT Dental College, Sangamner Taluka
4. Senior Lecturer, Department of Prosthodontics, SMBT Dental College, Sangamner Taluka
5. Tutor, Department of Prosthodontics, Daswani Dental College and Research Center, Kota Rajasthan

\section{CORRESPONDING AUTHOR}

Honey Jethlia, Senior Lecturer, Dept of Prosthodontics

Daswani Dental College and Research Center,

Kota , Rajasthan

E-mail: drhoney_82@yahoo.co.in

Ph: 00919901920537

\begin{abstract}
Edentulism is considered a poor health outcome and may compromise the quality of life. Although the number of adult losing their natural teeth is diminishing, there are still large numbers of edentulous adults in the population. Many patients experience difficulties in wearing or using dentures. In some cases they may not be prepared to accept the limited efficiency of dentures when compared to natural teeth they replace. Patient satisfaction is critical determinant in the success or failure of complete denture therapy. The prosthodontist needs a thorough knowledge of anatomy, physiology, pathology and psychology to treat these problems. This article is intended to assist practitioners in the management of those problems that in our experience occur most frequently.
\end{abstract}

KEY WORDS: Post insertion, Denture stomatitis, complete dentures, discomfort.

INTRODUCTION: Denture insertion represents the effort of series of carefully considered and exacting procedure on part of prosthodontist. The majority of patients with complete dentures are apparently well satisfied. According to Yoshizumi, Langer and Sheppard, satisfaction and comfort rate in good quality complete dentures varied between $69 \%-85 \% .{ }^{1}$ Unfortunately a small percentage of patients persistently seek adjustments. The sequence of denture adjustments, reline, remake can develop into a cycle with some individuals.

PERIODIC RECALL APPOINTMENTS FOR ORAL EXAMINATION 2, 3: The complete denture service cannot be adequate unless patients are cared for after the dentures are placed in the mouth. In many instances the most crucial time in the patient's perception of success and failure of denture is the adjustment period. Every denture wearing patient should be in a recall program, just as any other dental patient. Boucher has advised recall appointments immediately 24 hour post insertion and periodic check up phase. Sharry has advised four recall appointments after10 days, 3 weeks, 6 weeks and 3months consequently from denture placement. 


\section{POST INSERTION PROBLEMS CAN BE BROADLY GROUPED INTO 4:}

1. Looseness of dentures

i. Decreased retentive forces

ii. Increased displacing forces.

2. Discomfort associated with dentures

i. Related to impression surface of denture

ii. Related to occlusal surface

iii. Related to polished surface

iv. Related to possible systemic association

3. Support problems

4. Problems associated with retention and stability

5. Other difficulties

i. Noise on eating and speaking.

ii. Speech problems.

iii. Eating difficulties.

i. Altered taste sensation.

ii. Gagging (nausea).

1. LOOSE DENTURE: Sheppard ${ }^{5}$ revealed denture looseness as the main cause of complaint of denture wearers. This is more commonly associated with lower denture and usually brought to the dentist attention either soon after the dentures are placed or following a period of successful wear when the dentures are nearing the end of useful life.

\section{CAUSES OF LOOSE DENTURES}

i. Decreased retentive forces 4

a. Lack of seal because of border under extension in depth and width, resorption of residual ridge and inelasticity of cheek. The functional depth and width of the sulci should be utilized to provide seal and assist in optimal positioning of the teeth.

In case of residual ridge resorption and under extension border temporarily reline denture with tissue conditioner if stability restored, reline/rebase denture to functional impression ${ }^{6}$.In case of inelasticity of cheek slightly under-extend peripheries of dentures in both depth and width.

b. Air beneath the impression surface ${ }^{4}$ results in poor fit due to deficient impression, damaged cast, warped denture, over adjustment. These problems can be managed by

relining, if design parameters of denture are satisfactory. Ensure that areas of heavy contact between denture and tissues are relieved prior to impression making.

Warped denture can be corrected by using optimum curing cycle for acrylic resin, denture must not be heated when trimming and polishing and resultant cast must not be over trimmed or damaged.

c. Xerostomia ${ }^{7}$

For individual with xerostomia, retention can be a major problem. Management of xerostomia can be done by using artificial saliva to enhance retention and stability.

Stimulating saliva with bulky diet, chewing gum, sugar-free acidic sweets can be helpful.

d. Neuromuscular control problems ${ }^{4}$ are caused from change in shape relative to old dentures, high occlusal plane on lower denture and motor neurone disorder. Correcting any faults in 
denture hindering neuromuscular control, maintaining optimal retentive forces and minimize displacing forces on existing dentures can be helpful.

ii Increased displacing force 4

a. Overextension of denture borders in depth and width is managed by reducing over-extension, along with use of disclosing material if necessary.

b. Poor fit - tissue recoil is caused because of poor/inappropriate impression technique especially in posterior lingual area and is managed by relining if all design parameters are satisfactory, otherwise remake. Ensure that old denture is removed from the mouth $90 \mathrm{~min}$ prior to impression.

c. Occlusal ${ }^{8}$ problems such as intercuspal and retruded contact positions not coincident, lack of occlusal balance in protrusive, lateral excursions and excessive vertical overlap of anterior teeth results in loose denture. Such problems can be corrected by removing inappropriate contacts and adjusting occlusal contacts until balance is obtained.

\section{DISCOMFORT ASSOCIATED WITH DENTURES}

Discomfort is common complaint associated with denture. Soon after the dentures are fitted or after a period of successful wear. It is more commonly associated with lower denture.

i. Discomfort Related to Impression Surface 4

This may be caused due to pearls of acrylic or sharp ridge on fitting surface of denture, denture base not relived in region of undercuts, over-extended lingual flange-impinging on to mylohyoid ridge, or post dam too deep. Examine the impression surface for surface irregularities by using disclosing material to identify the position and extent of over-contour and relieve appropriately. Ensure that any trimmed acrylic is thoroughly polished prior to re-insertion.

ii. Discomfort related to polished surfaces 9 .

Patient complains of pain at posterior aspect of upper denture usually associated with opening movement. Discomfort may be due to too thick flange constraining coronoid process. Accurately define area involved using disclosing material, relieve and repolish.

iii Discomfort related to occlusal surfaces ${ }^{10}$

a) Pain on eating in presence of occlusal imbalance is because of anterior or posterior prematurity, incisal locking, or lack of balanced articulation. Determine occlusal prematurities and adjust occlusion by selective grinding.

b) Pain or inflammation on labial aspect of lower ridge is due to lack of incisal overjet causing incisal locking which is treated by reducing incisal vertical overlap and if appearance is compromised, resetting the incisors may be required.

c) Pain about periphery of dentures, possibly accompanied by pain in masseter and posterior temporalis muscles which tends to intensify as day progresses is due to vertical dimension of occlusion more than patient can tolerate.

d) Tongue biting. is usually due to combination of posterior teeth being placed in lingual position together with sharpness of cusps. Management done by reduction and smoothening of teeth on lingual aspect.

e) Cheek biting is likely to happen if width of sulcus is not restored. Restoration of functional sulcus width is advised to avoid cheek biting. Lip biting is due to absence of adequate lip 
support, excessive anterior horizontal overlap, corrected by grinding lower incisors to provide more incisal guidance angle.

iv Discomfort related to systemic factors ${ }^{11}$

a) Burning Mouth Syndrome ${ }^{12}$-Some patients complain of burning sensation in wearing complete denture. The symptoms are so severe that denture cannot be tolerated for more than few hours. It is relevant to differentiate between burning mouth sensation and burning mouth syndrome. In the former group the patient's oral mucosa are often inflamed or an allergic reaction. In patient suffering from burning mouth syndrome, the oral mucosa usually appears clinically healthy. Majority of patients affected from burning mouth syndrome are older than 50 years, females and wearing complete denture. The females are usually postmenopausal women. Burning Mouth Syndrome is managed by correcting any denture faults, antidepressant therapy, and good oral hygiene.

b) Herpetic ulcers are caused by herpes simplex or herpes zoster virus and are treated by prescription of appropriate medication (e.g. acyclovir) and oral hygiene instructions.

c) Patient allergic ${ }^{13}$ to denture material relate to higher residual monomer content of acrylic. This problem can be managed by rebasing denture using controlled heat cure cycle or making denture in polycarbonate or other non-polymethyl methacrylate resin, if excess residual monomer is detected.

d) Denture stomatitis ${ }^{14}$ (Denture-sore mouth, Inflammatory papillary hyperplasia, Chronic atrophic candidiasis) In present day population evidence of denture stomatitis is $50 \%$ among complete denture wearer. Chief complaint is burning or itching sensation of palatal mucosa. Usually has frictional element (ill-fitting denture) plus opportunistic candidal infection. Treated by advising tissue conditioner and cleaning of denture by scrubbing and soaking in hypochlorite solution is recommended. Antifungal therapy may also be required.

\section{SUPPORT PROBLEMS:}

a.) Fibrous displaceable ridge ${ }^{15}$ as forces of mastication cause denture to sink into and tilt on supporting tissues, thus disrupting retentive seal. Relining/ rebasing of denture, giving additional vent holes in labial/ buccal/ lingual flanges, and low-viscosity impression material can be used to manage the problem.

b) Bony prominence covered by thin mucosa ${ }^{4}$ (e.g. Tori, maxillary midline suture) denture rock over the prominence which may be covered with inflamed tissue. It is corrected by providing optimum balanced occlusal contacts to prevent rocking over the fulcrum tissues.

c). Pain avoidance mechanisms - To relieve pain produced by denture, tongue/cheeks lift appliance away from tissue or patient uses excessive amounts of fixative, or self applied reline material in attempt to relieve contact with supporting tissues. Eliminating the cause of pain is important.

d). Resorbed ridge $^{16}$ results in little resistance to forces in lateral and anteroposterior directions; hence dentures are liable to move. This is treated by allowing optimal border extension in depth and width, considering endosseous implants and surgical deepening of sulcus: if bone is insufficient for implants.

\section{PROBLEMS ASSOCIATED WITH RETENTION AND STABILITY17}


Retention as related to artificial dentures is the resistance offered to a force directed at right angles to the seating surface which tends to lift the denture from the supporting surface of the tissues. Stability refers to the maintenance of equilibrium and to the resistance to displacement when the masticatory forces act in general, towards the seating surfaces ${ }^{18}$. Most of the patients complained about the looseness and misfitting of their dentures. Additionally, loss of retention caused dissatisfaction of patients related to function. The loss of retention of the dentures may have impaired the patients' ability to chew. . This complication is the main reason of need for replacement of their dentures.

5. OTHER DIFFICULTIES : There are a number of other difficulties which are reported from time to time by complete denture patients. They are nevertheless important as they are not infrequently encountered in dental practice.

i. Noise on eating/speaking is because of excessive occlusal vertical dimension, occlusal interference, loose dentures. It is also found that porcelain teeth create more impact noise than acrylic. These are corrected by addressing specific faults or remake as required.

ii. Speech problems ${ }^{19}$ are usually uncommon but presence is of great concern to the patient. It may be because of new tongue positions, new occlusal relationships or new teeth orientation and it can be easily managed by ensuring that palatal contour should not allow excessive tongue contact or air leakage.

iii. Eating difficulties may result from unstable dentures, incorrect occlusal vertical dimension or blunt teeth which results from excessive abrasion of occlusal surface as a result of adjusted occlusion or prolonged wear. This can be corrected by accurate assessment of occlusal vertical dimension, and careful explanation of rationale is needed while using non anatomic teeth.

iv Appearance ${ }^{20}$ Although it has to be stressed that appearance cannot fully assessed until 4 to 6 weeks after insertion of finished denture. This is because of adaptation of lip and facial muscle to underline denture. Management is done upon accurate assessment of patient's aesthetic requirements, giving ample time to the patient to comment at the trial stage or using any available evidence- photographs / previous dentures.

v. Gagging21 is because of loose denture, thick distal border of upper denture or lingual placement of posterior teeth. Hence management ${ }^{22}$ is done by psychological assessment if indicated or use of conditioning appliance e.g. extended base for home use.

vi. Altered taste sensation 23

Dentures do not cover many taste buds, thus no physiological basis for this complaint Thickness and low thermal conductivity of acrylic base material could be the cause. This is managed by decreasing palatal cover so long as retentive forces deemed adequate.

CONCLUSION: The patient should be dealt with in a sympathetic manner, keeping in mind that such complaints are very important to patient. A careful scrutiny based on a thorough knowledge of normal and abnormal tissue response as well as of the fundamentals of complete denture prosthesis is essential in treating the problems connected with complete denture use. There are many ways that dentures can be improved, and dentists should be able to assess the quality of a denture in terms of aesthetics, support, retention, stability, occlusion, vertical dimension and extension of the denture bases. 


\section{REFERENCES:}

1. Yoshizumi DT. An evaluation of factors pertinent to the success of complete denture service. J Prosthet Dent 1964; 14:866-78.

2. George A Zarb, Charles L Bolender, Gunnar E Carlson. Bouchers prosthodontic treatment for edentulous patients. 11th Edition, chapter 3, Page 30.

3. John J Sharry. Complete denture Prosthdontics, 2nd edition,chapter 24, page 358.

4. A.A.Grant, J.R.Heath, J.F.McCord- complete prosthodontics problems, diagnosis\& management (1994)

5. Sheppard IM, Schwartz LR, Sheppard SM. Oral status of edentulous and complete denture-wearing patients. J Am Dent Assoc1971; 83:614-20.

6. Atwood,D.A. Reduction of residual ridges;a major oral disease entity. J Prosthet Dent $1971 ; 26 ; 266-279$

7. Turner M, Jahangiri L, Ship JA. Hyposalivation, xerostomia and the complete denture: a systematic review. J Am Dent Assoc. 2008 Feb; 139(2):146-50.

8. Hammond,J. and Thomson,J.C..Diagnosis of complete denture difficulties. Dental Update1982; 9:35-408.

9. Wright, SM, The polished surface contour: a new approach. International Journal of Prosthodontics1991; 4:159-163

10. Gunnar E. Carlsson, Odont Dr and Dr Odont HC. Clinical morbidity and sequelae of treatment with complete dentures. J Prosthet Dent 1998; 79 (1): 17-23.

11. Oral mucosal lesions associated with the wearing of removable dentures. BudtzJørgensen E. J Oral Pathol. 1981 Apr; 10(2):65-80

12. Tourne,L.P,Luc, P.M. and friction,J.R. Burning mouth syndrome. Oral Surgery, Oral Medicine, Oral Pathology 1992; 74:158-1674.

13. Nater JP, Groenman NH, Wakkers-Garritsen BG, TimmerLH. Etiologic factors in denture sore mouth syndrome. J Prosthet Dent 1978; 40 (4) : 367-73.

14. Arendorf,T.M.and Walker,D.M.Denture stomatitis review. Journal of Oral Rehabilition, 1987; 14:217-227. 4.

15. G. Van Huysen, Lieutenant Colonel William Fly and Major L. Leonard: Artificial Dentures and the Oral Mucosa. J Prosthet Dent 1954; 4 (4): 446-60.

16. Tallgreen, R. The continuing reduction of the residual alveolar ridges in complete denture wearers:a mixed longitudinal study.J ProsthetDent1972;27:120-132

17. Tuckfield WJ. The problem of mandibular denture. Aust J Dent. 1952;56(1):36-49.19.

18. Kuebker WA. Denture problems: causes, diagnostic procedures,and clinical treatment. 1. Retention problems. Quintessence Int 1984; 15: 1031-44.

19. Carr, L, Wolfaardt, J.F. and Haitas, G.P. Speech defects in prosthetic dentistry. Journal of the Dental Association of South Africa, 1985; 40:387-390

20. Brisman, A.S .Aesthetics: a comparision of dentist's and patients concepts. Journal of American dental association 1980; 100; 345

21. Conny D J and Tedesco L A. The gagging problem in prosthodontic treatment identification and causes. J Prosthet Dent 1983; 49:601-06

22. G. S. Bassi, BDS, G. M. Humphris, JThe etiology and management of gagging: A review of the literature J Prosthet Dent 2004;91:459-67.

23. Tahereh G, Fahimeh H R, Sepideh M K .Evaluation of the Effect of Upper Complete Denture on Gustatory and Olfactory Senses J Dent Res Dent Clin Dent Prospects. 2009 Autumn; 3(4): 132-135. 